\title{
Ensino Superior no Brasil: Internacionalização hoje e os acordos MEC-USAID
}

\section{Bianka de Jesus}

Mestranda em Educação Brasileira pela Universidade Federal do Ceará, Fortaleza, Brasil; bolsista do CNPq; Jornalista responsável pela Revista Ciência \& Luta de Classes e do Jornal INVERTA, membro do Escritório de Tradução da Agência Latino-Americana no Brasil (Prensa Latina-Cuba).

\section{Resumo}

O artigo parte da hipótese que a Internacionalização do Ensino, compreendida como intercâmbio cultural e científico, decorrente da universalização da Ciência e da integração econômica entre os povos, constitui-se em grande desafio para os países em desenvolvimento. Assim, ao trazer novamente à tona elementos do processo de internacionalização da educação forçada através dos acordos MEC-USAID (1965-1968), tece considerações sobre a atual inserção brasileira no processo de internacionalização do Ensino Superior, apresentando, através de dados institucionais, as formas de acesso ao ensino terciário.

Palavras-chave: Internacionalização do Ensino, integracionismo, intervencionismo, sistema-mundo capitalista, sociedade do conhecimento, roubo de cérebros.

\section{Resumen}

El artículo parte de la premisa que la internacionalización de la educación, entendida como un intercambio cultural y científico que resulta de la universalización de la ciencia y la integración económica de los pueblos, se constituyó en un gran desafío para los países en desarrollo. Así, al traer de vuelta a un primer plano los elementos del proceso de internacionalización de la educación forzada a través de los acuerdos MEC-USAID (1965-1968), teje consideraciones sobre la actual inserción brasileña en el proceso de internacionalización de la educación superior.

Palabras-clave: Internacionalización de la Educación, integración, intervencionismo, sistema-mundo capitalista, la sociedad del conocimiento, fuga de cerebros.

\section{Abstract}

The article starts from the premise that the internationalization of education, understood as the cultural and scientific exchange that resulted from the universalization of science and the economic integration amongst peoples, constituted a major challenge for developing countries. Therefore, by bringing 
back to the foreground elements of the forced process of internationalization of education through the MEC-USAID (1965-1968) agreements, it outlines considerations over the current process of Brazilian insertion in the internationalization of higher education by presenting, through institutional data, the different forms of access to this type of education.

Keywords: Internationalization of Education, integration, interventionism, capitalist world-system, knowledge society, brain drain. 


\section{Introdução}

O presente artigo tem como objetivo traçar algumas breves considerações sobre a inserção brasileira no processo de internacionalização do Ensino Superior, tendo em vista o passado não tão distante do processo de internacionalização forçada através dos acordos MEC-USAID (1965-1968).

O problema é demonstrar o quadro atual do ensino superior no Brasil, apresentando, através de dados institucionais, as formas de acesso ao ensino terciário, os principais programas educacionais do governo, e os desafios que estão colocados diante do país.

O trabalho parte da hipótese que a internacionalização do ensino, compreendida como intercâmbio cultural e científico, decorrente da universalização da ciência e da integração econômica entre os povos, constitui-se em um grande desafio para os países em desenvolvimento, diante de um cenário atual de crise do sistema-mundo capitalista. Este fato de per si compromete a inserção no que é denominado de sociedade do conhecimento, devido à crise do capital concentrar-se cada vez mais profundamente nos países desenvolvidos, como Estados Unidos, União Europeia, Japão, polos de atração da maioria absoluta dos estudantes no exterior. O conhecimento científico-técnico, - apropriado pelas classes dominantes dos países hegemônicos ao longo de séculos foi negado em parte, aos países e povos colonizados e sob o imperialismo.

A espoliação ao que se denominou de Terceiro Mundo tem como uma de suas modalidades o roubo de cérebros (braindrain), em que uma parcela da mão de obra qualificada destes países emigra para os centros hegemônicos dos Estados Unidos, Europa e Japão, em busca de melhores condições de sobrevivência e levam consigo os já escassos recursos investidos em sua formação acadêmica, enfraquecendo ainda mais em suas nações as condições de realizarem uma revolução científico-técnica para resolver os históricos problemas locais, como a fome e doenças; e ao mesmo tempo inserirem-se soberanamente no contexto global da denominada sociedade do conhecimento e da informação (LÓPEZ SEGRERA, 2009).

O Brasil, através do atual governo federal, tem buscado com vários programas e políticas ampliar o acesso de estudantes às instituições de ensino superior, levando a que, em uma década, mais brasileiros e brasileiras - jovens estudantes da escola pública em geral, não brancos (pretos, pardos e indígenas), uma maioria até então pouco vista nas faculdades - passasse a ter acesso às instituições universitárias. No marco deste esforço cresceu também a internacionalização do ensino superior, destacando-se o Programa Ciência Sem Fronteiras, lançado 2011, com o objetivo de consolidar e expandir a internacionalização da ciência e da tecnologia através do intercâmbio e da mobilidade internacional.

Porém, apesar desse fluxo de pessoas, conhecimentos, tecnologias, valores e ideias que vão além de fronteiras com a interconexão das instituições de ensino superior e a abertura do currículo a temáticas internacionais, a educação mantém as fronteiras nacionais como base analítica, pois a economia mundial, e por conseguinte a internacionalização, não podem ser vistas apenas como relações entre países, visto que existem múltiplas interações internas e externas para sua efetivação, que levam em conta os interesses dos países (governos) envolvidos, interesses econômicos, políticos e sociais. 
As diferenças entre integracionismo ${ }^{1}$ e intervencionismo ${ }^{2}$ devem ser analisadas integralmente para que países em desenvolvimento possam inserir-se nestas novas relações. Assim, a educação superior torna-se de fundamental importância para a tomada de decisões estratégicas. A concentração e centralização do desenvolvimento científico-técnico nos centros de poder hegemônicos do capitalismo, como Estados Unidos, Inglaterra, União Europeia e Japão, requer que o governo e as IES (Instituições de Ensino Superior) brasileiras encontrem alternativas encaminhadas à internacionalização da educação superior que favoreçam o desenvolvimento econômico e social da região, porém, com a firmeza de princípios de preservar e fortalecer-se enquanto Estado soberano.

$\mathrm{O}$ artigo está subdividido em: 1 Introdução; 2 Ensino Superior no Brasil; 3 A Internacionalização do Ensino Superior através do Ciência Sem Fronteiras, $4 \mathrm{O}$ intercâmbio universitário entre Brasil e Estados Unidos, 5 Os Acordos MEC-USAID e 6 Referências Bibliográficas.

\section{A Internacionalização do Ensino Superior}

Segundo o Censo de Educação Superior de 2012, o Brasil possui 6,7 milhões de universitários, o que representou em números absolutos, um acréscimo de $360 \mathrm{mil}$ matriculados em relação ao ano anterior. As instituições federais apresentaram um crescimento de $10 \%$ enquanto a rede particular chegou a 4,8\%. Esta ampliação do ensino superior permitiu o acesso aos estudantes que cursaram as escolas públicas em geral, especialmente as escolas localizadas fora do sudeste-sul do país, nas regiões menos desenvolvidas, contemplando segmentos da população antes excluída do ensino universitário: pobres, pardos e pretos, segundo declarações à imprensa do então Ministro da Educação, Aloizio Mercadante.

Ainda de acordo com o Censo do Ministério da Educação, as instituições federais ultrapassaram, pela primeira vez, a marca de 1 milhão de alunos de graduação, resultado da expansão iniciada no governo Lula, em 2001, e que se seguiu em seu segundo mandato e continua no Governo de Dilma Rousseff. Nesse período, os dados oficiais indicam que o total de ingressantes no Ensino Superior subiu 124,9\%, de 1 milhão para 2,3 milhões. As federais estão na vanguarda, com um incremento de $145,4 \%$, de 125 mil para 308 mil novos estudantes de 2001 a 2010 . O salto maior nas federais ocorreu de 2009 para 2010, quando esse número cresceu 19,2\%. A rede particular no ano seguinte aumentou em $134,3 \%$, de 792 mil para 1,8 milhão, com os cursos tecnológicos, respondendo por $12,9 \%$ das matrículas, o que representou a maior ampliação: 11,4\% em 2011.

Segundo o documento, o Instituto Nacional de Estudos e Pesquisas Educacionais Anísio Teixeira (Inep) e o Ministério da Educação (MEC) com o objetivo de mensurar a qualidade dos cursos de graduação no país utilizam o Índice Geral de Cursos (IGC), uma vez por ano, logo após a publicação dos resultados do Exame Nacional de Desempenho de Estudantes (Enade), em que uma média dos conceitos dos cursos

1 "Ideia ou condição de integração entre pessoas, coisas, situações, etc. Derivando de integrar com algo ou alguém”. http://www.dicionarioinformal.com.br/significado/integracionismo/4712/

2 "Doutrina que preconiza uma intervenção seja do Estado nos negócios privados, seja de uma nação ou em um conflito entre países. O fato de um Estado intervir nas lutas de outro Estado" (http://www.dicio.com.br?/ intervencionismo/) 
de graduação da instituição é utilizada, ponderada a partir do número de matrículas e das notas de pós-graduação de cada instituição de ensino superior.

\section{O Programa Ciência Sem Fronteiras}

O Ministério da Ciência, Tecnologia e Inovação (MCTI) e o Ministério da Educação (MEC), através do CNPq (Conselho Nacional de Desenvolvimento Científico e Tecnológico) e da CAPES (Coordenação de Aperfeiçoamento de Pessoal de Nível Superior), suas respectivas instituições de fomento, e Secretarias de Ensino Superior e de Ensino Tecnológico criaram, em 2011, o Programa Ciência sem Fronteiras (CSF), para "a consolidação, expansão e internacionalização da ciência e tecnologia, da inovação e da competitividade brasileira por meio do intercâmbio e da mobilidade internacional (CIÊNCIA Sem Fronteiras, 2014)".

O programa prevê a utilização de até 101 mil bolsas em quatro anos para promover intercâmbio de forma que alunos de graduação e pós-graduação façam estágio no exterior com a finalidade de manter contato com sistemas educacionais competitivos em relação à tecnologia e inovação. As áreas prioritárias do Programa são as engenharias e demais áreas tecnológicas; além de ciências exatas e da terra; biologia, ciências biomédicas e da saúde.

Segundo o Programa, para a graduação as universidades locais são responsáveis por definir, juntamente com a CAPES e o CNPq, os melhores cursos e instituições nos seus respectivos países. As instituições são avaliadas a cada chamada e o destino dos bolsistas é adequado à medida que o Programa recebe o retorno do relatório dos bolsistas. Na pós-graduação, após as propostas dos candidatos as instituições de destino são avaliadas pelo CAPES e CNPq.

\subsection{0 roubo de cérebros}

A internacionalização do ensino superior no Brasil também tem como desafio defender-se da migração altamente qualificada (MAC), segundo define a pesquisadora Camelia Tigau, do Centro de Pesquisa Sobre América do Norte (CISAN) da Universidade Autônoma do México (UNAM), o que não é outra coisa que o 'roubo de cérebros' (braindrain), termo utilizado quando a mão de obra de alto nível emigra para outras nações, principalmente devido à instabilidade econômica, e não retorna ao seu país de origem. Um exemplo é o que ocorre no México, o quarto lugar mundial como exportador de cérebros. Os profissionais mexicanos com alta qualificação, com pós-graduação e habilidades nas ciências, tecnologia e artes se incorporam aos emigrantes com baixa qualificação que vão para os Estados Unidos, mas ao contrário destes, são bem-vindos no país vizinho, como explica Tigau:

“(...) é necessário estudar a fundo o fenômeno migratório para ter uma visão integral do papel que desempenha o país na concorrência global para atrair recursos humanos”. (...) Se se fala de fuga de cérebros, faz-se referência a individuos qualificados naqueles que o país - em nosso caso - México-fez um investimento que se perde com seu êxodo (OAXACA Digital, 2012).

Assim, o CSF diante dessa realidade, busca como alternativa ao roubo de cérebros, o que se convencionou a chamar de 'circulação de cérebros' (braingain), quando estes 
trabalhadores altamente qualificados retornam aos seus países para aplicar localmente seus conhecimentos. A fim de 'resgatar' e atrair cientistas renomados e líderes de grupos de pesquisa no exterior de volta para o país, o Ciência Sem Fronteiras oferta diversas bolsas, como a do Pesquisador Visitante Especial e Auxílio à Pesquisa, com bolsas de Doutorado Sanduíche no Exterior e bolsa de Pós-Doutorado no Brasil. Além disso, o Programa busca atrair jovens cientistas ao país, principalmente brasileiros, por meio da concessão de Bolsa Jovens Talentos e Auxílio à Pesquisa, através da bolsa de Iniciação Científica - IC ou Iniciação Tecnológica e Industrial - ITI.

\section{0 intercâmbio universitário entre Brasil e Estados Unidos}

Entre 2012 e 2013 o número de brasileiros que foram para solo estadunidense em busca de intercâmbio universitário cresceu em 20\% entre 2012 e 2013, ocupando o $11^{\circ}$ lugar no ranking de estudantes estrangeiros. Segundo a pesquisa, em contrapartida, o país sul-americano registrou o segundo maior crescimento no mundo entre os destinos escolhidos por universitários americanos, correspondente a uma alta de 16,5\% em um ano, atrás apenas do Japão, onde a alta se explica pela queda abrupta no ano anterior após o desastre nuclear em Fukushima: "Estudam em universidades americanas 10.868 brasileiros; os estudantes estadunidenses no Brasil são 4.060. O Brasil contribui com 1,3\% dos estudantes estrangeiros nos EUA, 10.868. Per capita, os chineses mandam quase 3,5 vezes mais estudantes que o Brasil" (Folha de São Paulo, 2014).

O Jornal Folha de São Paulo divulgou recentemente o relatório Open Doors do Instituto de Educação Internacional em parceria com o Departamento de Estado norte-americano. Este relatório aponta que o Ciência Sem Fronteiras é maior responsável pelo aumento de $20 \%$ do número de universitários brasileiros nos EUA. As áreas humanas são a de preferência, apesar da ênfase dada pelo governo brasileiro aos cursos de engenharia e tecnologia da informação (TI), como se verifica na reportagem: dos brasileiros que estão estudando nos Estados Unidos somente 15\% cursam engenharia e computação, a maioria cursa humanas."

\section{Os Acordos MEC-USAID}

As propostas ditadas pela Organização Mundial do Comércio (OMC) para a internacionalização do ensino no Brasil são profundamente intervencionistas e deixam claras as intenções dos EUA no que se refere à solicitação da inserção da educação no Acordo Geral sobre o Comércio de Serviços (GATS) da OMC, em dezembro de 2000. Nessas propostas, a educação, ao contrário de ser um bem público, se remeteria à condição de mercadoria, voltada apenas para a lucratividade; ou seja, ao abrir o mercado brasileiro para o estabelecimento de universidades estrangeiras, tais instituições formariam mão de obra em áreas pré-definidas a fim de atender aos interesses externos, desvalorizando a cultura brasileira e até a soberania nacional, como afirmou Teles (2005), que acrescenta: "ao invés de acrescentar qualidade e crescimento de mão de obra no Brasil, contribuiria, sim, para a disseminação, confusão cultural seguida de popularização de outras culturas (...).” 


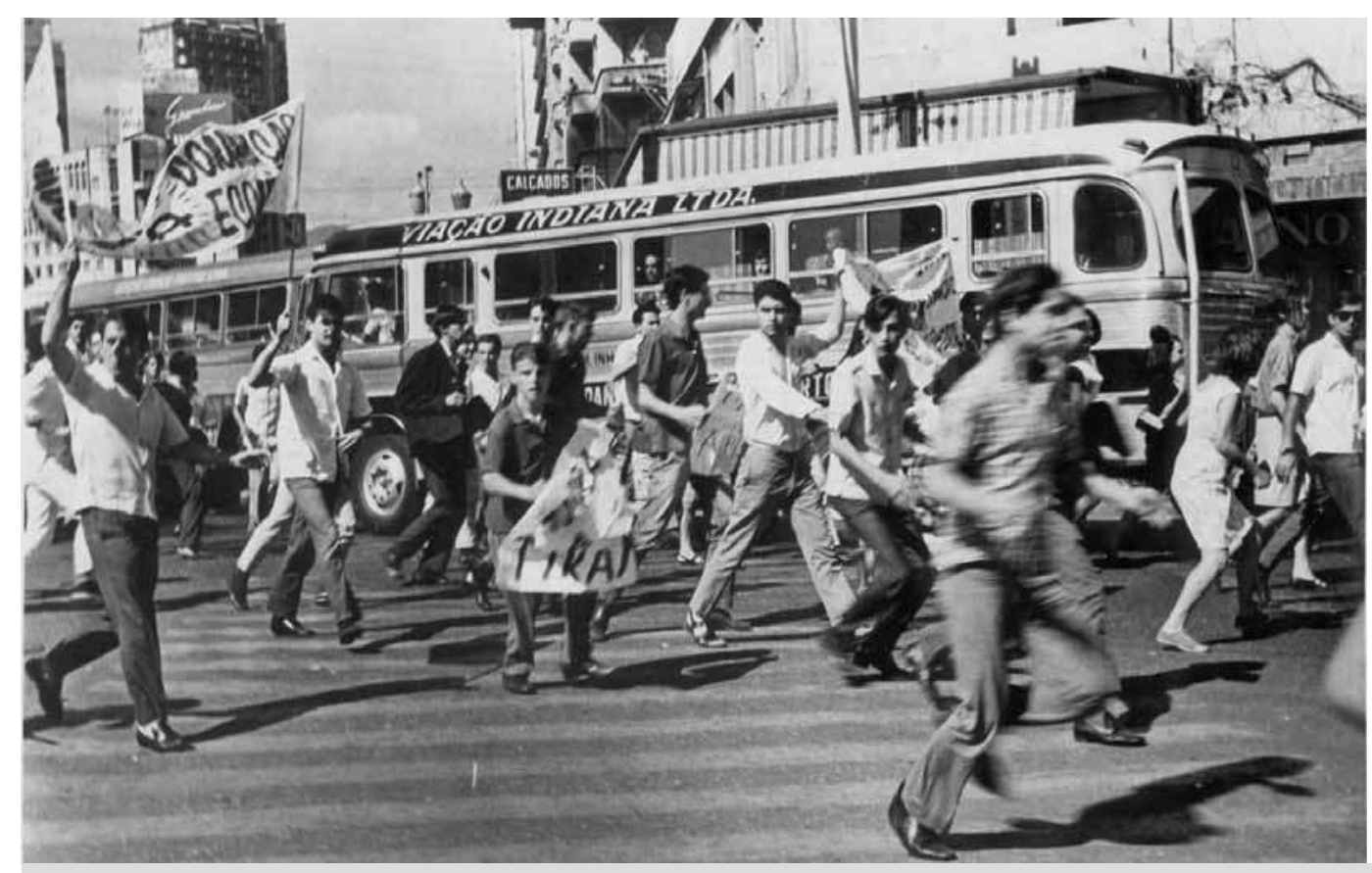

Manifestação contra os acordos Mec-Usaid (Fonte: http://www.arquivoestado.sp.gov.br).

Sob o regime imposto pelo GATS, as instituições de ensino estariam sujeitas às regras da OMC para que não haja qualquer indício por parte dos estados nacionais de um "impedimento para o comércio", dessa forma além da perda de soberania está institucionalizado o que Jonathan Kozol designa como a "sobrevivência dos filhos dos mais adaptados" (Survival of the Children of the Fittest), tornando-se regra, em todo o mundo, sistemas de educação e de segurança social segregativos, e abandonando coletivamente o sonho de direitos universais. A criação das chamadas worldclass para a elite do mundo e um sistema segregativo - ou simplesmente sistema nenhum — para aqueles que não contam, como denunciou Maude Barlow, presidente do Conselho dos Canadianos e uma ativista dos direitos dos cidadãos, ao site português resistir.info.

Uma breve pesquisa sobre o tema da defesa de nossa soberania frente à ameaça de uma proposta de internacionalização do ensino intervencionista, como a do GATS da OMC, remete-nos ao passado recente de intervenção dos Estados Unidos no Brasil, através dos acordos entre o Ministério da Educação (MEC) e a United States Agency for International Development (USAID), realizados durante a ditadura civil-militar, iniciada em 1964 e que perdurou por três décadas, cujos efeitos na sociedade brasileira se fazem sentir até os dias atuais.

Ao todo foram 12 acordos assinados, que contemplavam desde o ensino fundamental até o ensino superior. Um exemplo desse projeto ocorreu no antigo primário, uma vez que sob o pretexto de aperfeiçoá-lo, entre outras medidas, realizou-se a junção do mesmo com o ginásio e diminuiu-se a carga horária das matérias de ciências humanas; passando pelo ensino médio e tornou o inglês obrigatório na grade escolar (InformAndes, 2014). O acordo assinado em 31 de março de 1965 atuou nos conselhos e secretarias de educação para remodelar os planos de ensino e treinar técnicos brasileiros na prestação de consultorias permanentes, o MEC - Conselho de Cooperação Técnica da Aliança para o Progresso - o CONTAP/USAID em que o MEC se comprometia com o custeio da operação e a USAID entraria com a 
assessoria de técnicos norte-americanos para "modernizar" o ensino superior e cortar custos, tais técnicos atuariam em 18 universidades brasileiras (LIRA, 2010). Estes acordos estão inseridos em uma conjuntura marcada pelo tecnicismo educacional da teoria do capital humano, que preconiza a educação como um dos pressupostos para o desenvolvimento econômico. Pactuado em 23 de junho de 1965, as primeiras informações só vieram ao conhecimento público em novembro de 1966 (ALVES, 1968). Oficialmente tinham o objetivo de estabelecer convênios nos quais a USAID brindaria o país sul-americano no campo educacional com assistência técnica e a cooperação financeira, porém, o objetivo era fornecer as diretrizes políticas e técnicas para uma reorientação do sistema educacional no país, à luz das necessidades do desenvolvimento capitalista internacional:

"Os técnicos dos Estados Unidos que aqui vieram tinham como prioridade não a educação brasileira, mas a garantia da adequação de seu sistema de ensino aos interesses da economia internacional, sobretudo, aos das grandes multinacionais estadunidenses. Na prática, os acordos MEC-USAID apesar de não significarem mudanças diretas na politica educacional, influenciaram decisivamente os programas e diretrizes que passaram a conduzir o processo de reforma da educação no Brasil sob a Ditadura Militar. Destacam-se a Comissão Meira Mattos, criada em 1967, e o Grupo de Trabalho da Reforma Universitária (GTRU), de 1968, ambos decisivos na reforma universitária (Lei $\left.n^{\circ} 5.540 / 1968\right)$ e na reforma do ensino de $1^{\circ}$ e $2^{\circ}$ graus (Lei $n^{\circ}$ 5.692/1971)"(Idem).

Os acordos MEC-USAID buscaram implementar uma reforma para impor o modelo estadunidense nas universidades brasileiras, como denunciam Menezes e Santos (2002):

“(...) o ensino superior exerceria um papel estratégico porque caberia a ele forjar o novo quadro técnico que desse conta do novo projeto econômico brasileiro, alinhado com a politica norte-americana. Além disso, visava a contratação de assessores americanos para auxiliar nas reformas da educação pública, em todos os níveis de ensino".

Um dos pontos polêmicos dos acordos referia-se não somente à transformação das universidades brasileiras em fundações, uma tentativa a mais de restrição das escassas oportunidades de ingresso dos estudantes oriundos do proletariado ("pequena classe média e do operariado ao ensino superior") ao que, em tese, lhes daria uma possibilidade de ascender socialmente, como colocaria todo o sistema universitário brasileiro dependente direta e imediatamente do poder econômico dos Estados Unidos, como esclarece Alves (1968):

"A razão é simples. As fundaçôes não teriam, para garantir sua sobrevivência econômica, nem o compromisso de verbas federais que crescessem com as suas necessidades, nem a de recursos próprios, independentes, que lhes poderiam ser propiciados, por exemplo, com a transferência de ações das grandes empresas estatais para sua propriedade. Somente sobreviveriam e se expandiriam se dispusessem de doações particulares."

Os acordos tinham como previsão de término após dezoito meses, entre julho de 1966 e setembro de 1968, porém os efeitos continuariam muito além. Até 1970, o 


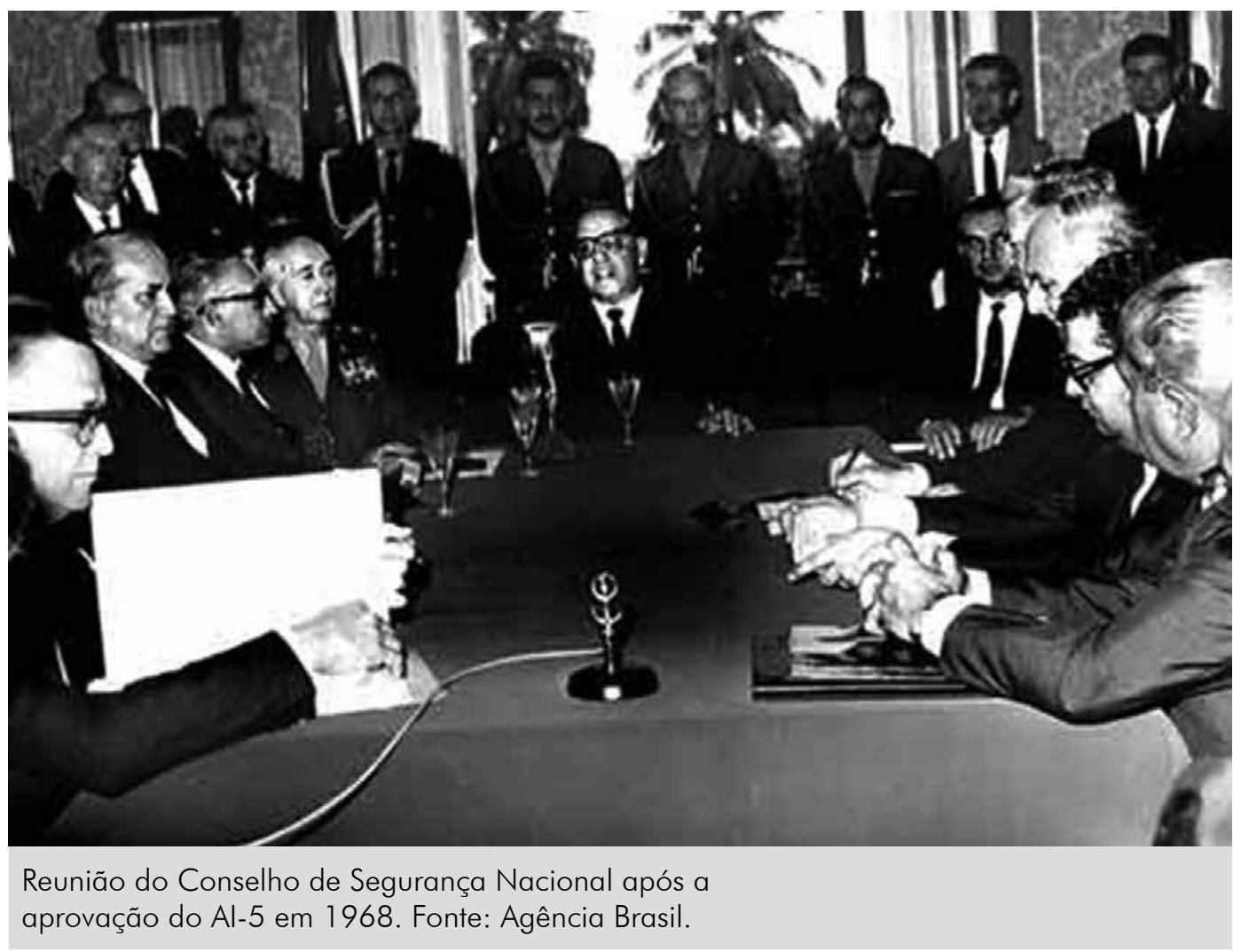

acordo atingiria, pelo menos, a 25\% das universidades brasileiras em sua estrutura. Não houve revisão do prazo para que as estruturas das demais universidades fossem modificadas na dependência do trabalho realizado, além disso, como denuncia Alves: há uma "estranha" coincidência no fato de prever o acordo a reestruturação de 18 universidades e estar o Ministro Tarso Dutra constantemente a falar em 18 universidades que deveriam reformar-se dentro dos prazos e condições estabelecidos por decretos-leis do Marechal Castelo Branco" (ALVES, 1968).

Diante da resistência levantada nos meios intelectuais e estudantis, que foram colocados na ilegalidade após o AI-5, contra os acordos MEC/USAID, o governo criou, em 1968, um Grupo de Trabalho encarregado de estudar a reforma e propor outro modelo, porém, pouco se soube onde começou e quando realmente foi suspenso o acordo.

\section{Conclusão}

Após observarmos os limites das ações no marco do sistema do capitalismo para uma definitiva independência científico-técnica do Brasil, deve-se igualmente reconhecer que esse movimento, trará em si contradições para o próprio sistema e seus gestores, ao levar o conhecimento científico à parcela significativa da população mesmo sem consciência político-ideológica totalmente formada, mas só isso já representa um passo após as políticas entreguistas da ditadura militar e dos governos neoliberais após a "abertura política”, o governo Collor e os dois governos de Fernando Henrique Cardoso.

É inegável o esforço dos últimos três governos para a integração econômica e educacional do Brasil no processo de globalização. Porém, não se pode limitar a 
contextualização do Ensino Superior, da Ciência e da Educação em geral, às medidas destes governos gerenciadores do capitalismo. Uma vez que movem-se, apesar das intenções, ações e programas de caráter progressistas, dentro do paradigma do capitalismo em crise, que exige um novo paradigma para a sociedade, a ciência e a educação (BEVILAQUA, 2012).

As tendências atuais da educação terciária dentro do marco da sociedade do conhecimento estão frente à conjuntura mundial com fortes tendências de mudanças profundas do sistema capitalista, como diz López Segrera (2009):

“(...) Las tendencias actuales de la educacion superior y de la sociedad del conocimiento están inmersas en un escenario de posibles cambios radicales do sistema-mundo. Todos los sistemas tienen vidas finitas y el sistema-mundo capitalista está abocado a cambios vertiginosos y profundos en la primera mitad del siglo XXI. Es posible que este sistema se este alejando del equilibrio y acercándose a un punto de bifurcación en el que podremos optar por diversos futuribles. Algunos incluso afirman que como sistema-mundo ha llegado a una crisis terminal (...) Lo que si es obvio, es que el desarrollo de la sociedad del conocimiento tiene lugar en un marco signado por la complejidad y la incertidumbre como nuevo paradigma cientifico y teórico y en una transición sistémica desde el punto de vista bistórico."

Outro aspecto fundamental é que o Ensino Superior no Brasil não se propõe no afã de inserir-se globalmente, a discutir o conceito da educação para o trabalho, majoritariamente subsumido ao paradigma do trabalho alienado, que não reconhece a sua face oculta, o trabalho criativo (JESUS, 2013), que é um elemento crucial do hiato educacional entre países em desenvolvimento e países desenvolvidos e dentro destes próprios países, o hiato educacional entre classes sociais, contradição que move as diferenças entre a internacionalização intervencionista e a integracionista. A ausência desse debate exclui do processo de internacionalização o aspecto da dualidade educacional: a educação voltada para as elites e a educação voltada para os trabalhadores, o que exige dos países em desenvolvimento o duplo desafio, de vencer os obstáculos no plano da internacionalização da Educação Superior no que diz respeito aos seus aspectos intervencionistas e o obstáculo interno, da educação de classe. Desafios que exigem, mais que políticas educacionais bem intencionadas, uma revolução de paradigmas (BEVILAQUA, 2012), tanto para os objetivos gerais da sociedade quanto para os da educação.

\section{Referências Bibliográficas}

BEVILAQUA, Aluisio Pampolha, Crise do capital em Marx e suas implicações nos Paradigmas da Educação: Contribuição ao repensar pedagógico no século XXI. Rio de Janeiro: Inverta Editora; Fortaleza: Edições UFC; 2011.

Ciência sem fronteiras, disponível em: http://www.cienciasemfronteiras .gov.br/web/ csf/. Acesso em 13/01/2014.

JESUS, Bianka de, Fundamentos da Avaliação da Educação: Trabalho Alienado ou Trabalho Criativo? Fortaleza: Projeto de dissertação do Mestrado em Educação Brasileira pela UFC; 2013.

Folha de São Paulo. Brasil e EUA têm maior aumento de universitários intercambistas. Disponível em http://www1.folha.uol.com.br/educacao/2013/11/ 1371205-brasil- 
-e-eua-tem-maior-aumento-de-universitarios-intercambistas.shtml. Acesso em $16 / 01 / 2014$.

LIRA, Alexandre Tavares do Nascimento. A Legislação de Educação no Brasil Durante a Ditadura militar(1964-1985): Um Espaço de Disputas. f. 364-367. Tese (Doutorado em Ciência Social) Instituto de Ciências Humanas e Filosofia, Universidade Federal Fluminense; 2010.

LÓPEZ SEGRERA, Francisco. Educación Superior y Producción del conocimiento en el Marco de La Globalización: Tendencias actuales de la sociedad del conocimiento. http:// doctoradosociales.com.ar/wp-content/uploads/2013/04/10.-TEMA-2.-SC-REDESTIC-MEGA.pdfhttp://doctoradosociales.com.ar/wp-content/uploads/2013/04/10.TEMA-2.-SC-REDES-TIC-MEGA.pdf.

MENEZES, Ebenezer Takuno de e SANTOS, Thaís Helena dos. MEC/USAID (verbete). Dicionário Interativo da Educação Brasileira - EducaBrasil. São Paulo: Midiamix Editora, 2002, http://www.educabrasil.com.br/eb/dic/dicionario.asp?id=325, Acesso em 20/1/2014.

MOREIRA, Márcio Alves. Beabá dos MEC-USAID. Rio de Janeiro: Edições Gernasa; 1968. 